\title{
Data collection using electronically assisted interviews in a roadshow
}

\section{- a methodological evaluation}

\author{
Rita Marcella \\ Professor of Corporate Communication, Aberdeen Business School, The Robert Gordon \\ University, Garthdee Road, Aberdeen, UK, AB10 7QE \\ e-mail: r.c.marcella@rgu.ac.uk
}

\section{Graeme Baxter}

Research Assistant, Aberdeen Business School, The Robert Gordon University, Garthdee Road, Aberdeen, UK, AB10 7QE

e-mail: g.baxter@rgu.ac.uk

\section{Nick Moore}

Managing Partner, Acumen, Brompton Ralph, Taunton, UK, TA4 2RU

e-mail: nick.moore@acumenuk.co.uk

Keywords: Information seeking, Parliament, Devolved legislatures, Technology

Word count: ca 7,760 words

\begin{abstract}
This paper discusses the second stage of a pilot study, funded by the Economic and Social Research Council, which investigated the impact of technology on the communication of parliamentary information to the general public. This second stage tested the application of a new data collection tool - an interactive, electronically assisted interview delivered in a roadshow environment. The approach was tested in the context of the public's need for information about the UK Parliament, the Scottish Parliament and the National Assembly for Wales. Interviews were carried out by a researcher, aboard a minibus equipped with a laptop and mobile data transmission equipment, who assisted members of the public in exploring and responding to parliamentary and devolved assembly websites. Roadshows took place across the UK at organisations such as public libraries, community centres, sheltered accommodation and universities. This paper discusses in critical detail all aspects of the execution of the methodology and draws conclusions as to its validity for future research.
\end{abstract}




\section{INTRODUCTION AND BACKGROUND TO THE RESEARCH}

This paper describes a pilot study funded by the Economic and Social Research Council (ESRC), the purpose of which was to test the application of a new data collection tool - an interactive, electronically assisted interview delivered in a roadshow environment. The paper presents a reflective review of the methodological approach adopted, discussing in critical detail all aspects of the execution of the methodology and drawing conclusions as to its validity for future research. The discussions begin by reviewing methodological approaches to gathering data about the general public's information seeking behaviour before moving on to an examination of the success of the roadshow approach. The approach was tested in the context of the public's need for information about the Westminster Parliament and devolved legislatures across the UK, although it might usefully be applied to gather data about any kind of information need. The roadshow approach was developed in an attempt to gather data from all groups in the community and not only those with an expressed or obvious need for parliamentary information, and was devised as a means of getting close to the everyday lives of those studied.

Methodologically, information behaviour research has moved from an early reliance on positivist surveys to the use of diverse methodologies in a mix of quantitative and qualitative research tools, enabling a more holistic view of information need to emerge, according to Weingand (1993), from the researcher getting 'close to the data, thereby developing the analytical, conceptual and categorical components of explanation from the data itself'. Early studies by Line (1967) and Lipetz (1970) review the methodological problems associated with the investigation of users' information needs, arguing that such a mixed approach is necessary in order to minimise the deficiencies associated with each methodology individually. Although the influential Baltimore study (Warner, Murray and Palmer, 1973) was based upon a rigorously tested interview schedule, Price (1984) argues that questionnaires and interviews tend to reveal only what the user thinks and not the actualities of behaviour. The INISS Project (Wilson and Streatfield, 1977; Wilson, Streatfield and Mullings, 1979), in a reaction against the 'relative sterility of survey based research', was conceived as a qualitative programme, using observation, in-depth qualitative interviewing and a participative research mode, in order to ensure triangulation of data. Sturges and Chimseu (1996) also defend the use of qualitative methodologies, despite acknowledging their limitations in proving hypotheses, in a combination of interdisciplinary approaches. 
There has been valid work based upon both questionnaire (Horner and Thirlwall, 1989; Hallmark, 1994) and interviews (Bichtler and Ward, 1989; Palmer, 1996; Hernon and MetoyerDuran, 1992). Palmer (1996), for example, uses semi-structured in-depth interviews to probe the information seeking behaviour of scientists, using cluster analysis to identify cluster groups amongst respondents. Ellis (1993) and Ellis, Cox and Hall (1993) use a technique based upon modelling from the results of personal interview. Eager and Oppenheim (1996) discuss a pilot using an observational non-questioning method of investigating user information needs, which is however less useful where a large group is to be investigated, and where there is little predicted similarity in the needs of the group. Wilson (1999) has recently developed a methodology designed to blend a qualitative approach with the collection of a great deal of quantitative data on various aspects of the information seeking process, employing a mix of interviewing, tape recordings of searcher/client interactions, logs of online searches and follow up interviews.

Research has also developed into human-computer interaction in information seeking, encouraging the use of a variety of new data collection instruments, such as transaction log analysis (Jansen, Spink and Saracevic, 2000) and verbal protocol analysis (Blackshaw and Fischhoff, 1988; Ericsson and Simon, 1993; Nahl and Tenopir, 1996), to provide a record of online search processes, recording respondents' intentions and decisions in association with an electronic $\log$ of actual search actions. Nicholas (1996) uses a complementary mix of interviews, questionnaires and transaction log analyses, while Hert and Marchionini (1997) have explored the users of U.S. statistical websites via online interviews, focus groups, content analysis of e-mail information requests, impressionistic analysis of online comments, usability tests and transaction log analyses.

The present researchers (Marcella and Baxter, 1999a, 1999b, 2000, 2001) have used a variety of methodological tools, in particular the survey by doorstep interview, to build a holistic and informed view of information need and information seeking in a range of communities, echoing the move in information behaviour research from a subject and cognitive approach to the person-centred one described by Wilson (1994). Their theoretical stance is primarily phenomenological but they believe there has been a good deal of relatively sterile debate as to the respective merits of quantitative and qualitative data collection tools and that these, it should be borne in mind, are merely tools that serve the theoretical stance of the researcher which may be positivist or interpretive. The roadshow is an attempt to develop a large-scale data collection tool, designed to utilise both quantitative and qualitative techniques in support of what is held to be an interpretive and phenomenological research perspective. 
The present project consisted of two stages, the first of which took the form of interviews with representatives of parliamentary and devolved assembly public information services. However, this paper will focus on the second element, the electronically assisted interview executed during roadshow events, as this is a novel approach which was being piloted.

\section{THE ROADSHOW APPROACH}

The research team sought to develop a new semi-structured interview methodology: an interactive, electronically assisted interview with members of the public that would be taken out across the UK as part of a pilot roadshow in an attempt to get close to the everyday lives of respondents. The main objective of these interviews was to explore the actual benefits or drawbacks for the general public of technologically supported approaches to parliamentary information, particularly for certain groups deemed to be in danger of exclusion.

The interviews were carried out by a researcher, aboard a minibus equipped with a laptop and mobile data transmission equipment, who assisted members of the public in exploring and responding to a number of parliamentary and devolved assembly websites, thus enabling the complementary and simultaneous collection of two types of data - logs of online search data and qualitative response to open questioning - that are normally collected via two distinct collection instruments. Given that it is notoriously difficult to encourage members of the public to participate in data collection activities, it was thought that this approach would enable better understanding of information seeking behaviour from both an observational and interactive perspective, when the respondent group would not have agreed to two separate forms of data collection, in the form of a search followed by an interview. It was also believed that the interactive interview held the potential for the research to probe, at the time of its occurrence, the reasons for search behaviour. Certainly, it was felt that such realtime searching, with participants having unrestricted access to all areas of the appropriate websites, would produce more extensive and illuminating data on the public's use of online parliamentary information than, say, the method used by BMRB International, where a Computer Assisted Personal Interviewing (CAPI) system allowed members of the public to respond to a standard series of video clips of proposed technologies for delivering online government services (Cabinet Office Central IT Unit, 1998). It was proposed that roadshow events conducted in England would focus on the UK Parliament website; in Scotland, the Scottish Parliament website; and in Wales, the website of the National Assembly for Wales. 
From the outset the Research Team were conscious that encouraging high levels of participation would be a challenge and the research design was, therefore, informed throughout by a consciousness of the importance of reducing demotivational factors. As it was felt that a standard minibus might not be sufficiently attractive to potential interviewees, alternative vehicles, such as a mobile library and a Health Information bus, better suited to the personal interview situation and with computer facilities, were investigated. However, both proved impractical for the short-term pilot, although such dedicated mobile accommodation would be desirable in a full-scale follow up study. The minibus, hired for the roadshows, had removable seats to create an interview area; and laminated posters, inviting people to, for example, 'Hop aboard and surf the Scottish Parliament website for free' were displayed in the windows.

The Researchers were conscious that technological problems interrupting the flow of the interviews would discourage participants and much thought, therefore, went into their preparation. In order to remain self-sufficient and mobile during the roadshows, it was proposed that a laptop computer and cellphone-based data transmission equipment be used. However, at the outset of the project, mobile technology within the UK allowed a maximum data transmission speed of only 9.6 kilobits per second (Kbps). The appearance of the Nokia Card Phone 2.0 and Orange High Speed Data service was, therefore, timely in offering transmission at up to $28.8 \mathrm{Kbps}$. Whilst download times were still noticeably longer than with the traditional, land-line based approach, it was felt that these were likely to prove acceptable to interviewees. Working with such mobile technology necessitated back-up battery support and researcher time spent on recharging. A transaction log package, spIE, was used to log invisibly all web pages visited online, recording the date, time and complete URL.

The reliability of the mobile communications was also crucial: if a mobile signal was not received then the interview could not proceed. A back-up was therefore made of 30 pages from each of the three websites on CDs. In the event, strong signals were obtained at all roadshow locations, with only three (or $4 \%$ ) of all interviews being affected by Internet access problems. 


\section{Target groups and locations for roadshows}

The roadshow targeted a sample of groups representative of: those in danger of social exclusion; those with little or no experience of using computers; and those thought likely to be in a position already to make fuller use of ICTs.

- older people

- single mothers

- ethnic minorities
- people in rural communities

- the business community

- academics

An event was planned with each during a week-long roadshow in each of three locations (i.e. Newcastle, Cardiff and Aberdeen), giving a total of 18 roadshows.

It was felt unlikely that there would be a constant stream of interviewees boarding the minibus of their own volition and, in an attempt to guarantee high numbers and to introduce an element of quota sampling, the team contacted a reputable market research company, specialising in recruiting interviewees for research purposes. The estimated cost of this method of recruitment, however, was outwith the scope of the project budget. It was also felt that the process of interviewee recruitment was an integral part of the piloting process and that its execution by a member of the Research Team enabled the more thorough evaluation of its success, as well as allowing a variety of lessons to be learned.

The approach adopted was for the roadshows to be associated with a host organisation that would both act as a reference point and lend authority to the event from the perspective of potential interviewees. However, finding six appropriate organisations in each location willing and able to host a roadshow event, within a tight schedule, proved complex. Some difficulties arose because of the timing of the project in the main summer holiday period, when fewer activities were taking place. In other cases, the structure of the organisation and the nature of its services proved a barrier to participation. For example, one drop-in centre for young families on low incomes in Aberdeen could not guarantee that anyone would drop in on a particular day. This co-ordinator was also sceptical about the likely response from the centre's users, particularly given the 'political' subject matter of the research. Such resistance or bias on the part of potential hosts was not uncommon and limited the potential pool of organisations available. Other organisations were dubious about potential response for other reasons. One support centre in Newcastle, aimed primarily at women from ethnic minority groups, and whose staff and volunteers are all women, declined to host an event as it was felt 
that its users/clients would feel intimidated by the presence of a male researcher. While the co-ordinator of a support group for lone parents in Aberdeen believed that members would be concerned about a potential breach of confidentiality, and also that they would not wish to be stigmatised as 'single mothers'. Some potential hosts (particularly in Cardiff) simply failed to reply and, although the Cardiff Libraries and Information Service stepped into the breach, this reliance on public libraries as hosts resulted in a series of Welsh roadshows rather different from that envisaged originally. It is, therefore, vital that careful consideration be afforded in the research design to the selection of host organisations and that sufficient time be allowed in planning for the process of negotiation to take place.

Although the business community had initially been a target for roadshow events, there was, unfortunately, a distinct lack of appropriate events during the relevant dates with which the roadshows could be tied in. Those which took place were intensive, paid events, where it was anticipated that few participants would be willing to spare the time to be interviewed. As a result, no roadshows aimed specifically at the business community took place. This is a community from which it is notoriously difficult to gather data via conventional means; while it is felt that the roadshow could be useful with the group, these must be planned well in advance of data collection to coincide with timely events such as trade shows and exhibitions.

In the event, it proved impossible within the prescribed timescale to arrange 18 roadshows. Only 15 took place, five in each geographic area, and these were conducted between August and October, 2001. Of the 15 events, nine exclusively involved targeted groups (three with the academic community, three with older people, one with ethnic minorities, one with a rural community and one with single mothers). The remaining six events involved a greater crosssection of the population, although most were arranged with a realistic hope of including individuals belonging to the targeted groups. Unfortunately, only three hosts were able to provide parking facilities suitable for the minibus; the rest (12) of the roadshow events had to be conducted indoors. However, it is felt that the 'roadshow' concept was as significant and as effective when held within an organisation's premises as when it took place in the visually mobile minibus environment. In both instances events were taking place closer to respondents' everyday lives than would otherwise have been the case and with less disruption to participants. The exception was the business community, where individual pre-scheduled sessions should be held at respondents' workplaces in any future use of the roadshow approach, in particular focusing upon business communities in a tight-knit geographic area, such as a retail or development park. 


\section{The Roadshows}

Circumstances unfortunately precluded a planned pre-pilot event in Aberdeen, and the interview schedule and technology were tested for the first time 'in the field' in the Newcastle area. It quickly transpired that the estimated interview time of 25-30 minutes acted as a disincentive to respondent participation. As a result, this was modified to an estimated 15-20 minutes; although in practice the actual interview times varied considerably, from three to over 45 minutes.

Although the majority of the roadshows were held during Parliamentary and Assembly recess periods, there is no evidence to suggest that these recesses had any impact on the public's response to the roadshow events. Equally, although promotional posters were displayed by host organisations, these did not raise levels of participation. Throughout the entire series of roadshows no-one directly approached the interviewer asking to explore one of the websites: all participants were 'recruited' by means of the interviewer approaching them individually or as part of an assembled group, indicating that the process of recruitment must be built into the planning of the execution of any event. Although participants were informed about the purpose of the research and assured of their anonymity, they were not asked to sign any form of agreement or disclaimer: however, in the light of data protection concerns, it is recommended that this be done in future roadshows.

\section{Host organisations and roadshow events in the Newcastle upon Tyne area}

Negotiation with potential host organisations was, as has been seen, a protracted and difficult process. The organisations which agreed to participate are outlined briefly below to give a flavour of their variety and the population to which they gave access. Although these represent a variety of potential users, the Research Team feel that with more time and a greater consciousness of the ways in which organisations might be encouraged to participate, a more varied and appropriate selection of organisations might have been assembled.

Gateshead Library. At the time of the roadshow, Gateshead Libraries were coordinating a 'Summer Surfing' scheme, a programme of free Internet sessions. As Gateshead has a large orthodox Jewish community, it was hoped that access to members of ethnic minority groups might be achieved. Library users were approached while they used the computer or reference facilities. 
Age Concern Newcastle upon Tyne. The organisation had just appointed an IT trainer and installed two computers with Internet access in their café, where this roadshow took place. A significant proportion of non-participants declared a wariness or fear of the technology, although this was eased when reassurance was provided by the Age Concern IT trainer and/or by individuals who had already taken part in an online session. Four interviewees, all novice computer users, preferred to participate in pairs, for further reassurance and support. Novice users had particular difficulties in operating the mouse.

Sure Start Newcastle East. A social development initiative, aimed at disadvantaged parents and children. This roadshow took place during a family fun day held at the programme's headquarters. The majority of the parents present were single mothers. In the first roadshow event to use the minibus, a degree of 'bribery' (in the form of free pens and yo-yos for the children present) was required to attract adult interviewees. Although the overall level of adult participation was not all that was hoped, there was a constant stream of children visiting the minibus, giving the 'feel' of the type of roadshow originally envisaged.

Park Road Community Centre, Newcastle. The Centre is located in Cruddas Park, an area with one of the highest proportions of ethnic minority groups in the city, and regarded locally as somewhat 'rough'. There were no parking facilities immediately outside the centre's entrance and it was therefore necessary for the minibus to be physically detached from the host organisation. A very poor response was obtained, with only one participant. Events resulted in the interviewer becoming selective (and thus biased) when approaching potential interviewees, in particular as a result of an episode when a woman, on her own, appeared genuinely alarmed at being invited onboard the minibus.

University of Northumbria. The event was held in the Learning Resources Centre, supporting the Faculty of Health, Social Work and Education. Interviews were conducted with staff and with users in the computer and journals area.

\section{Roadshow events in the Cardiff area}

Cardiff roadshows were affected by public hostility towards the Assembly. A significant proportion of those approached had voted against its formation, and regarded it as an expensive 'talking shop' with few useful powers. Equally, the pages on the Assembly website 
took longer to download than those on the UK Parliament site. In general, these download times were acceptable, but, at times, some respondents became visibly impatient.

Rumney Library, Cardiff. Hosts an Age Concern 'Good Neighbours Scheme'. The minibus was located immediately outside the library entrance, and this appeared to dispel any wariness or suspicion amongst potential interviewees, as well as any feelings of detachment or insecurity on the part of the interviewer. However, participant numbers were small, suggesting that the minibus approach is more appropriate when it can be tied in with an 'event' of some description.

Grangetown Library, Cardiff. Caters for the large Asian community living in the area and is also a National Assembly for Wales Information Link library, providing access to Assembly publications.

Rhiwbina Library, Cardiff. The busiest branch library in Cardiff. The roadshow took place in the library's vestibule.

Senior Health Shop, Barry. A project aimed at promoting better health in later life, coordinated by Age Concern. The roadshow took place in the snack bar. All four participants refused to use the mouse.

Cardiff University. Held within Cardiff University's Arts and Social Studies Resource Centre. The interviewer was located opposite the main entrance, close to the information desk and a computer area.

\section{Roadshow events in the Aberdeen area}

During the Aberdeen roadshows, while some scepticism about the Scottish Parliament was encountered, the level was not nearly as marked as in Wales. A very small number of the individuals approached regarded the Scottish Parliament as having a central Scotland bias, or as being corrupt. (It should be noted that the roadshows took place a few weeks prior to the controversial resignation of Henry McLeish as First Minister). Secondly, as anticipated, download times for Scottish Parliament website pages were slower than for UK Parliament pages. In the majority of cases, these download times were manageable, but the retrieval of lengthy documents and documents in Portable Document Format proved problematic. 
Bressay Brae Sheltered Housing Complex. Operated by a non-profit making housing cooperative. Its common room was about to take delivery of a computer with Internet access. Initial interest in the roadshow was low, but, on observing participants using the laptop, other residents began to approach, look on and ask questions about the project and the Scottish Parliament website.

Inverurie Library. One of Aberdeenshire's three Scottish Parliament Partner Libraries (providing access to parliamentary publications), and chosen because of its rural location. This event was held in the library's computer area.

University of Aberdeen. Held in the Taylor Library, which houses a law collection, UK and Scottish Official Publications, and a European Documentation Centre. The interviewer was given use of a project room in which to conduct the interviews.

Aberdeen Mosque. This took place between the final two prayer sessions of the day. This was the only roadshow to take place during the evening and connection and download times proved embarrassingly slow, bringing into question the suitability of current mobile technology for evening Internet access.

Kincorth Library. One of Aberdeen's three Partner Libraries; in the week prior to the roadshow it had hosted a Scottish Parliament exhibition.

\section{Overall public response to roadshow events}

Table I illustrates the numbers approached during each roadshow, the numbers of participants and the reasons for non-participation. 


\begin{tabular}{|c|c|c|c|c|c|c|c|}
\hline \multicolumn{8}{|c|}{$\begin{array}{l}\text { Table I: Roadshow events: numbers approached, participants and reasons } \\
\text { for non-participation }\end{array}$} \\
\hline \multirow[b]{2}{*}{ Host Organisation } & \multirow[b]{2}{*}{ Approached } & & & \multicolumn{4}{|c|}{ Reasons for Non-participation } \\
\hline & & \multicolumn{2}{|c|}{ Participated } & \multirow{2}{*}{$\begin{array}{c}\begin{array}{c}\text { Too } \\
\text { Busy }\end{array} \\
14\end{array}$} & \multirow{2}{*}{$\begin{array}{c}\begin{array}{c}\text { Not } \\
\text { Interest. }\end{array} \\
11\end{array}$} & \multirow{2}{*}{$\begin{array}{c}\begin{array}{c}\text { Afraid } \\
\text { of IT }\end{array} \\
-\end{array}$} & \multirow{2}{*}{$\begin{array}{c}\text { Other } \\
3\end{array}$} \\
\hline Gateshead Library & 33 & 5 & 15 & & & & \\
\hline Age Concern, Newcastle & 35 & 7 & 20 & 6 & 8 & 10 & 4 \\
\hline Sure Start, Newcastle $\varnothing$ & 12 & 5 & 42 & - & 7 & - & - \\
\hline Park Rd CC, Newcastle $\emptyset$ & 29 & 1 & 3 & 17 & 11 & - & - \\
\hline Univ. of Northumbria & 18 & 6 & 33 & 12 & - & - & - \\
\hline Rumney Lib., Cardiff $\emptyset$ & 21 & 5 & 24 & 9 & 7 & - & - \\
\hline Grangetown Lib., Cardiff & 22 & 3 & 14 & 8 & 11 & - & - \\
\hline Rhiwbina Lib., Cardiff & 41 & 6 & 15 & 16 & 19 & - & - \\
\hline Age Concern, Barry & 25 & 4 & 16 & - & 16 & 5 & - \\
\hline Cardiff Univ. & 55 & 9 & 16 & 30 & 16 & - & - \\
\hline Bressay Brae, Abdn. & 20 & 3 & 15 & - & 17 & - & - \\
\hline Inverurie Library & 41 & 11 & 27 & 12 & 18 & - & - \\
\hline Univ. of Aberdeen * & 89 & 9 & 10 & 21 & 7 & - & 2 \\
\hline Aberdeen Mosque & 12 & 2 & 17 & - & 8 & - & 2 \\
\hline Kincorth Lib., Aberdeen & 13 & 3 & 23 & 4 & 6 & - & - \\
\hline Totals * & 466 & 79 & 17 & 149 & 162 & 15 & 11 \\
\hline
\end{tabular}

\section{Notes}

ø Minibus used during roadshow

* 50 potential interviewees addressed as part of large, assembled groups, so reasons for non-participation not known

In summary, during the Newcastle roadshows just under 130 people were approached and 24 agreed to participate; a response rate of around 19\%. In Cardiff, just over 160 people were approached and 27 were interviewed, giving a response rate of $17 \%$. While in the Aberdeen events, 28 from around 180 people approached agreed to participate: a response rate of $16 \%$. Overall, over 460 people were approached and 79 were interviewed, giving a total response rate of $17 \%$.

At first glance, this response rate might appear rather disappointing, certainly when compared with that obtained in some of the previous surveys of the general public conducted by the Research Team. For example, a questionnaire survey of the European Union information needs of users in three Scottish public library authorities achieved an 83\% response rate (Marcella and Baxter, 1997); while a national survey of the citizenship information needs of the UK public, where questionnaires were distributed in public libraries, Citizens Advice Bureaux, and other information and advice agencies, attained an overall response rate of $46 \%$, with a 69\% response rate in public libraries (Marcella and Baxter, 1999a, 1999b). However, it should be emphasised that the data collection tools used in these two surveys were relatively short, self-completion questionnaires. A more meaningful comparison, therefore, might be made with the present authors' second national survey of citizenship information 
need, this time conducted by extended doorstep interview, where each one of 12 interviewers had to visit an average of 570 households in order to successfully complete their individual quota of 75 interviews, giving an overall response rate of 13\% (Marcella and Baxter, 2000, 2001). In terms of the response, an accurate comparison with other recent studies of the information needs or the information seeking behaviour of the general public, particularly those relating to the use of electronic information resources, is difficult, largely because potential participants' refusal rates are often unspecified. For example, Coles (1999), in a study of the use and non-use of CD-ROMs in public libraries, interviewed just under 300 people at 9 different libraries, with potential interviewees being approached as they entered the building, but details of the numbers refusing to be interviewed are not provided. What can be said, however, is that the number of participants in this present study (79) compares favourably with those in similar, practical studies of online behaviour. Toms (1999), for example, used transaction logs and retrospective verbal protocols when examining the use of digital newspapers by 50 participants 'solicited' from coffee shops, public libraries, universities and the local community net (these participants were compensated for their time); while, Light (2001), in part one of a three-part study of users' responses to websites, videoed the think-aloud processes of 14 'target users' while they explored three websites concerned with the 1997 UK general election.

As potential interviewees at the roadshow events were, on occasions, addressed as part of a large assembled group, it was not always possible to establish their reasons for nonparticipation. Where reasons were given, refusals could be divided almost equally between those individuals who were not interested in the topic (48\%) or were too busy to participate (44\%). Other, more specific reasons were given by $3 \%$ of those approached. A further $5 \%$ of refusals (all from older people) were because of an expressed unwillingness to use the computer; although the interviewer's impression was of a far higher proportion of nonparticipants, particularly older people, with an unexpressed fear of the technology, who preferred to indicate that they were either not interested or too busy. There were no significant differences in the reasons for non-participation between the three geographic locations. Indeed, when considering the potential impact of other demographic factors few patterns emerge, although when compared with the sample as a whole, a significantly higher proportion $(72 \%)$ of refusals amongst the academic community were due to a lack of time.

Clearly, encouraging the public to participate is a challenge to any methodology seeking to explore the public's information behaviour; the 'political' emphasis of the present project heightened that challenge. However, to achieve a $17 \%$ response rate in a pilot situation, where by definition lessons are in the process of being learned about the execution of the 
methodology, would suggest that this is an approach which has real merit for those engaged in research of this kind.

The response should also be viewed in terms of gathering data from a varied sample of the population, and in particular from groups that might be deemed to be in danger of exclusion. The Research Team's previous questionnaire surveys conducted in public libraries (Marcella and Baxter, 1999a, 1999b) had resulted in samples that, demographically, were fairly representative of the UK population, but which came to a greater extent proportionally from professional and managerial occupations than for the UK as a whole; while the survey by doorstep interview (Marcella and Baxter, 2000, 2001) was more successful in reaching the less literate respondent, economically inactive groups and those from lower socio-economic grades. With the present roadshow study, while the sample was proportionally representative of the UK population as a whole, in terms of both gender and ethnicity, it was also particularly successful in reaching older and economically inactive people. The proportion of the sample aged 65 or over (22 of 79; 28\%) was almost double that (15\%) for the UK as a whole; while the proportion (60 of $79 ; 76 \%$ ) that was economically inactive (i.e. those individuals that were neither in employment nor actively looking for work) was significantly higher than the UK figure of just under 50\% (Office for National Statistics, 2001).

However, two major factors must be borne in mind in research design: that there may be a bias to be overcome in encouraging participation, whether that be lack of willingness to discuss politics or fear of the technology; and that both the researcher and the respondent may feel exposed in carrying out such research in an exclusive and potentially unsafe environment.

\section{THE INTERVIEW SCHEDULE}

Three versions of the interview schedule were designed, one for each of the three websites being studied. That used in the Aberdeen roadshows can be seen at Appendix I. The versions used in Newcastle and Cardiff varied only in referring to the appropriate legislature.

The schedule comprised four distinct parts focusing on:

1) Respondents' demographic characteristics - age, ethnicity, occupation and education. 
2) Structured questions on past need for, and use of, parliamentary and devolved assembly information, voting patterns and levels of political participation, and previous experience of computers.

3) A free-form period of undirected information seeking, on the appropriate website, for information on a suggested or chosen topic. The ten suggested topics were included to overcome potentially wasted time spent in uncertainties over what might be interesting, based on one of the Research Team's experience conducting interviews with women with a fear of IT (Marcella, 2002). The topics were:

- Child care

- Pensions and welfare benefits

- Single European Currency

- Long-term care for the elderly

- Equal opportunities
- Foot and Mouth

- Public transport

- Fuel prices

- Student tuition fees

- Hospital waiting lists

Eighteen $(23 \%)$ respondents selected one or more of the suggested topics, 28 (35\%) chose a topic of their own, while 33 (42\%) preferred to browse generally.

4) Structured questions about the user friendliness of the website, the relevance and comprehensibility of information and the likelihood of their revisiting the site in future.

The data from structured questions were analysed conventionally using a statistical package. Overall, the interviews enabled a rich and illuminating dialogue to take place between the researcher and the interviewee. The search activities taking place focused the discussion on relevant areas where participants were prepared to open up, not only about the experience of online searching on the chosen websites, but also about their feelings and attitudes politically and their response to public events. Although clearly response was variable, with interviews ranging from three to 45 minutes, in general participants were prepared to devote time and critical thought to the process.

In order to allow for an open elicitation of respondents' thoughts, the free-form sessions, utilised verbal protocol analysis, where the respondents were asked to 'think aloud' as they progressed with their search. In line with the experience of others utilising this method, some respondents found it difficult to maintain a constant verbal report of their thoughts and actions and a greater incidence than had been anticipated of prompts and additional questions from 
the interviewer were required. A common prompt was to ask the respondent for his/her general thoughts on the language and terminology used in the website being examined; but additional questions relating to specific features of the website, or respondents' particular navigational approaches, were also asked. For example, during the sessions on the UK Parliament website, the following questions were amongst those asked:

"Could you see yourself ever e-mailing your MP?"

"Is the site map generally your first port of call when you visit a website?"

Given the need to develop conversational rapport and to put the respondent at his/her ease, these prompts were essential. To an extent they had been pre-planned into the research design. However, in the execution of a comfortable interaction between the researcher and the interviewee, it was found that impromptu discussion tended to take place around the activities taking place online. In order to ensure a systematic approach, they should in the future be built into the interview schedule in a more predictable manner.

Many respondents clearly felt uncomfortable about thinking aloud in the presence of others. While this may have affected what they were saying, it certainly affected their audibility. Those interviews held in a private location, or contrarily in a noisier location, generally elicited less self-conscious comment. Attention to the physical location is therefore significant to success of interviews. Respondents frequently took the opportunity to voice opinions on unrelated topical issues, as in the Cardiff roadshows which took place in the week following the terrorist attacks on 11 September 2001. This is not a problem that can be excluded, in that at any given point in time there will be incidents dominating the media and the public's consciousness. Indeed, it is felt that such public events might even be built into the roadshow execution as a means of encouraging responsiveness and enabling interviewees to open up in discussion. Prompts might therefore, focus on search activity or might range further afield in encouraging reflection about the respondent's life experience.

All of the think aloud sessions were recorded on audio tape which proved problematic at times, as a result of inaudible respondents, noisy locations and interference from the card phone signals. As a result, the subsequent transcription process proved laborious and timeconsuming. Transcriptions were coded manually using a specially designed coding scheme, developed in a protocol analysis approach. The 19 categories within this scheme were constructed as the transcription progressed and are designed to reflect the nature of the actual comments made and the behaviour exhibited during the search sessions, by both the interviewee and the interviewer. 
Twelve interviewee codes with an IE prefix were assigned:-

IE Search. When the interviewee had structured a search, with little or no assistance or guidance from the interviewer.

IE Browse. The interviewee had no specific search outcome in mind, but simply browsed the website.

IE Navigate. The interviewee asked navigational questions or questions about the website's structure.

IE Read aloud. The interviewee read aloud the contents of a particular page of the website.

IE Read internal. The interviewee read the contents of a particular page of the website 'internally'.

IE Positive. The interviewee made a positive qualitative comment about the content or particular design features of the website.

IE Negative. The interviewee made a negative qualitative comment about the content or particular design features of the website.

IE Parliament. The interviewee made comments on, or asked questions about, parliamentary procedure or terminology.

IE IT. The interviewee made comments on, or asked questions about, the software and hardware being used, or computers and the Internet in general.

IE Project. The interviewee asked questions about, or commented on, the research project.

IE Political. The interviewee voiced his/her opinions on particular political and current issues. 
IE Personal. The interviewee gave personal information, relating to work or study experiences, previous use of computers, or to a specific life incident.

Six interviewer codes with an IR prefix were assigned:-

IR Search. The interviewer provided the interviewee with specific instructions or advice on formulating a search.

IR Navigate. The interviewer provided specific navigational instructions or advice, or answered questions on website structure.

IR Question. The interviewer asked questions when the interviewee failed to maintain a constant verbal report of their thoughts and actions, or when a specific matter of interest arose during the search.

IR Parliament. The interviewer provided an explanation of parliamentary procedure or terminology.

IR IT. The interviewer provided an explanation of, or answered questions on, the technology used in the project, or on computers and the Internet in general.

IR Project. The interviewer provided further details of the research project.

The last of the 19 codes is Interruptions, indicating that the interview was interrupted. These may have been verbal, by the interviewee's family or friends or other individuals; or they may have been for technical reasons. Given the open nature of the interview process and the impracticable environment in which some of the interviews were conducted, the protocol codes emerging would appear to cover all the forms of behaviour that are likely to arise in this context and might be used with confidence in any future application of the method.

Transcription and analysis may be on the basis of the frequency of verbal statements (Blackshaw and Fischhoff, 1988; Nahl and Tenopir, 1996) or on the time spent on particular protocols (Gilhooly and Green, 1996). The latter option was chosen and, while the coding was comprehensive, transcription was selective, focusing on meaningful statements. While the data has, to date, been analysed according to the codes set out above, the Research Team 
plan to analyse according to both approaches in order to evaluate comparatively the validity and usefulness of each.

\section{CONCLUSIONS AND RECOMMENDATIONS}

The Research Team feel that the roadshow as a means of executing interactive, electronically assisted interviews has proved its capacity to act as an effective instrument in gathering data from a representative sample of the general public about their information needs and information seeking behaviour. It enabled a free exploration of technologically delivered information by individuals who may or may not have ever demonstrated a conscious need for such information, allowed them to respond to and evaluate that information, and elicited a rich stream of data about the relevance of such information to their lives.

However, given that the pilot was designed to test the approach experientially, naturally a number of very valuable lessons have been learned from using the roadshow approach to executing interviews and these are briefly noted in conclusion.

For a full-scale roadshow event, a vehicle should be commissioned that would reflect the requirements of the interview process, enabling semi-private discussion between two interviewers and two interviewees with a laptop positioned conveniently for each. This arrangement would ensure that the interviewee felt comfortable in expressing freely their personal experience and opinion. It is also recommended that the vehicle have a logo designed specifically for the project, which would appeal to a wide group of potential respondents, yet convey the purpose and authority of the project. However, the vehicle should also have clear and unimpeded windows, to ensure that respondents do not feel that the sessions are overly confidential and potentially 'unsafe' occasions.

Despite concerns about the reliability of laptop and mobile communications technologies in a roadshow environment, few problems were encountered in the stability of access, largely due to careful pre-planning and testing. In any future research it will be necessary to ensure adequate back-up and to determine whether there have been any further technological advances that might improve the process further.

A highly significant aspect of roadshow planning and scheduling is that of selecting, and negotiating with, appropriate host organisations with which the event may be associated. This complex and time consuming process may have a highly material impact on the success of the 
project overall. Equally, it may be necessary to convince the organisation's representatives of the value and relevance of the research to the group served, overcoming some observable bias amongst potential participants. While a variety of organisations were prepared to host roadshows, it is felt that this is an area of the research which might have been improved.

Gender issues were also raised in respect of the potential discomfort of certain user groups with being interviewed by a male researcher and the perceived lack of safety in female interviewees being alone, in a minibus, with a male interviewer. It is essential that a full-scale survey involve the concurrent presence of both male and female researchers. It was felt by the representatives of some organisations that certain groups would not wish to be stigmatised by being categorised as, for example, 'single mothers', which would suggest that there are also social tensions to be observed in negotiating with certain groups. Given that the roadshow has particular strength in enabling access to excluded groups, such as older and economically inactive people, who are notoriously difficult to target by traditional means, the Research Team feel that the co-operation of a range of appropriate host organisations is vital and should, for any subsequent researcher utilising this approach, be built into research design in a realistic manner. It is particularly important that potential hosts be convinced of the value of the research outcomes and that promotional materials highlighting that value be produced.

It is recommended that an alternative approach be adopted in taking roadshows to the business community, a group which proved particularly difficult to target. It is recommended that the roadshow be taken to businesses, by arranging visits to industrial parks etc., having arranged scheduled interviews with individuals in advance. In the event, it is not seen as a serious deficiency of the pilot that data could not be collected from the business community, as this group did not represent a major focus of the research.

The roadshow was found to operate as effectively in a virtual as in a real or literal sense. Although some of the roadshows were held in the minibus, many took place within the premises of the associate organisation. It is the mobility of the concept rather than its physical manifestation that is significant. The roadshow was successful in getting out into communities, close to respondents' individual, everyday lives.

The timing of the schedule of roadshow events may be critical to their success in terms of the recruitment of interviewees. In a larger scale survey these should be timetabled to avoid any predictable points when host organisations and participants are not following a conventional pattern of behaviour. Parliamentary recess periods did not, however, appear to be influential. 
Despite efforts to promote the roadshows, potential interviewees did not actively approach the researcher but instead had to be approached. It is felt that promotional materials are, therefore, of little benefit and that the emphasis should be placed upon providing information and reassurance about the purpose of the roadshow while it is taking place, rather than attracting participants in advance. It is also vital that researchers are able to reassure potential participants and are prepared to enthuse them about the research agenda.

When soliciting interviews, it may be important for the researcher to be accompanied by either a representative of the host organisation or by a member of this group who has already participated in interviews. This is likely to increase the rate of positive response and reassure, in particular, those who may be nervous of the technology or uncertain of the purpose of the researcher. The potential of group participation in the interview should also be considered further, as there is some evidence from the pilot to suggest that reluctant individuals are prepared to take part in such a collective event, in particular amongst older interviewees or those who are nervous of the technology. Other forms of incentive or reward may be necessary to attract participants, particularly if the event is a fun or leisure one. Monetary reward may in fact be the simplest and most effective, in line with the practices of market researchers.

The interviews were found to be a successful tool in collecting data that illuminated the processes whereby respondents formulated and carried out searches. The only difficulty found was associated with some individuals' discomfort with the practice of "thinking aloud" unprompted. It was necessary for the researcher to use prompts and additional questions throughout, in particular to elicit qualitative commentary. This should be planned systematically for future exercises. It is also recommended that individual interviews take place in some degree of privacy so that respondents may be more relaxed about voicing their thoughts. Future use of group interviews would require an observer in addition to conventional data recording techniques. Crucial to the success of the recruitment of participants and execution of the interview is the establishment of a positive rapport between the researcher and the interviewee. It is important that an open conversation develop, rather than an interrogation. The researcher undertaking data collection using this methodology must be approachable, flexible and able to adjust his/her communications style to the individual respondent. The relative 'maturity' of the researcher may also be influential in achieving good rapport with the interviewee.

This methodology successfully gathers a variety of interlinked forms of highly informative data, via a single data collection tool, in order to achieve simultaneously both a rich source of 
revealing information about the actual search behaviour and qualitative reflections upon that behaviour. The overall response rate to requests to participate in the electronic interactive interview was acceptable at $17 \%$, in comparison with other surveys of the general public, as in for example the authors' previous survey executed via doorstep interview (Marcella and Baxter, 2001, 2002); and the resultant sample size compared favourably with those in similar web-based studies of information seeking behaviour. The methodology was successful in enabling the collection of data from a varied sample of the population and in particular from excluded groups. As an approach, such interviews conducted via roadshow events add to the existing phalanx of methodological tools available to the information behaviour researcher. While other approaches may be more useful with a constrained user population, the present approach is particularly effective in overcoming the difficulties associated with gathering illuminating data from the public as a whole. 


\section{REFERENCES}

Bichtler, J. and Ward, D. (1989). "Information seeking behaviour of geoscientists", Special Libraries, Vol. 80 No. 3, pp. 169-178.

Blackshaw, L. and Fischhoff, B. (1988), "Decision making in online searching”, Journal of the American Society for Information Science, Vol. 39 No. 6, pp. 369-389.

Cabinet Office Central IT Unit (1998), Electronic government: the view from the queue, Cabinet Office, London. Available at:

www.e-envoy.gov.uk/publications/reports/viewqueue/index.htm (accessed August 2002).

Coles, C. (1999). "Information seeking behaviour of public library users: use and non-use of electronic media", in Wilson, T. D. and Allen, D.K. (Eds), Exploring the contexts of information behaviour: proceedings of the second Information Seeking in Context Conference, 13/15 August 1998, Sheffield, Taylor Graham, London, pp. 321-329.

Eager, C. and Oppenheim, C. (1996), "An observational method for undertaking user needs studies", Journal of Librarianship and Information Science, Vol. 28 No. 1, pp. 15-23.

Ellis, D. (1993), "Modelling the information-seeking patterns of academic researchers: a grounded theory approach", Library Quarterly, Vol. 63 No. 4, pp. 471-486.

Ellis, D., Cox, D. and Hall, K. (1993), “A comparison of the information seeking patterns of researchers in the physical and social sciences", Journal of Documentation, Vol. 49 No. 4, pp. 356-359.

Ericsson, K. A. and Simon, H. A. (1993). Protocol analysis: verbal reports as data, MIT Press, Cambridge, MA.

Gilhooly, K. and Green, C. (1996), "Protocol analysis: theoretical background", in Richardson, J. T. E. (Ed), Handbook of qualitative research methods for psychology and the social sciences, BPS Books, Leicester, pp. 43-74.

Hallmark, J. (1994). "Scientists' access and retrieval of references cited in their present journal articles", College and Research Libraries, Vol. 55 No. 3, pp. 201-209. 
Hernon, P. and Metoyer-Duran, C. (1992), "Discussion forum: the public", Government Information Quarterly, Vol. 9 No. 1, pp. 1-10.

Hert, C. A. and Marchionini, G. (1997), Seeking statistical information in Federal websites: users, tasks, strategies, and design recommendations. Final report to the Bureau of Labor Statistics. Available at ils.unc.edu/ march/blsreport/blsmain.htm (accessed August 2002).

Horner, J. and Thirlwall, D. (1989). "Online searching and the university researcher", Journal of Academic Librarianship, Vol. 14 No. 4, pp. 225-230.

Jansen, B. J., Spink, A. and Saracevic, T. (2000), "Real life, real users and real need: a study and analysis of user queries on the web", Information Processing and Management, Vol. 36 No. 2, pp. 207-227.

Light, A. (2001), "The influence of context on users' responses to websites", The New Review of Information Behaviour Research, Vol. 2, pp. 135-149.

Line, M. B. (1967), Library surveys, Bingley, London.

Lipetz, B. (1970), "Information needs and uses", in Cuadra, C. A. and Luke, A. W., (Eds), Annual review of information science and technology, American Society For Information Science, Washington, DC, Vol. 5, pp. 3-32.

Marcella, R. (2002), "Women on the web: a critical appraisal of a sample reflecting the range and content of women's sites on the Internet, with particular reference to the support of women's interaction and participation", Journal of Documentation, Vol. 58 No. 1, pp. 73-96.

Marcella, R. and Baxter, G. (1997), "European Union information: an investigation of need amongst public library users in 3 Scottish authorities", Journal of Librarianship and Information Science, Vol. 29 No. 2, pp. 69-75.

Marcella, R. and Baxter, G. (1999a), "The information needs and the information seeking behaviour of a national sample of the population in the United Kingdom, with special reference to needs related to citizenship", Journal of Documentation, Vol. 55 No. 2, pp. 159183. 
Marcella, R. and Baxter, G. ( 1999b), "The citizenship information needs of the UK public: the quest for representativeness in methodological approach", in Wilson, T. D. and Allen, D.K. (Eds), Exploring the contexts of information behaviour: proceedings of the second Information Seeking in Context Conference, 13/15 August 1998, Sheffield, Taylor Graham, London, pp. 304-320.

Marcella, R. and Baxter, G. (2000), "Information need, information seeking behaviour and participation, with special reference to needs related to citizenship: results of a national survey", Journal of Documentation, Vol. 56 No. 2, pp. 136-160.

Marcella, R., and Baxter, G. (2001). "A random walk around Britain: a critical assessment of the random walk sample as a method of collecting data on the public's citizenship information needs", The New Review of Information Behaviour Research, pp. 87-103.

Nahl, D. and Tenopir, C. (1996), "Affective and cognitive searching behaviour of novice endusers of a full-text database", Journal of the American Society for Information Science, Vol. 47 No. 4, pp. 276-286.

Nicholas, D. (1996), "An analysis of the online searching behaviour of practitioner end users", Journal of Documentation, Vol. 52 No. 3, pp. 227-251.

Office for National Statistics (2001), Social Trends 2001 edition, The Stationery Office, London.

Palmer, J. (1996), "Scientists and information: I. Using cluster analysis to identify information style", Journal of Documentation, Vol. 47 No. 2, pp. 105-129.

Price, S. (1984), Information support for independent advice centres, British Library Research and Development Department, Boston Spa.

Sturges, P. and Chimseu, G. (1996). "Qualitative research in information studies: a Malawian Study”, Education for Information, Vol. 14 No. 2, pp. 117-126.

Toms, E.G. (1999), "What motivates the browser", in Wilson, T. D. and Allen, D.K. (Eds), Exploring the contexts of information behaviour: proceedings of the second Information Seeking in Context Conference, 13/15 August 1998, Sheffield, Taylor Graham, London, pp. 191-207. 
Warner, E. S., Murray, A. D. and Palmour, V. E. (1973), Information needs of urban residents, US Department of Health, Education and Welfare, Office of Education and Bureau of Libraries and Learning Resources, Washington, DC.

Weingand, D. (1993), "Grounded theory and qualitative methodology", IFLA Journal, Vol. 19 No. 1, pp. 17- 26.

Wilson, T.D. (1994), "Information needs and uses: fifty years of progress", in Vickery, B.C. (Ed). Fifty years of information progress: a Journal of Documentation review, Aslib, London, pp. 15-51.

Wilson, T. D. (1999), "Exploring models of information behaviour: the 'Uncertainty' Project", in Wilson, T.D. and Allen, D.K. (Eds), Exploring the contexts of information behaviour: proceedings of the second International Conference on Research in Information Needs, Seeking and Use in different contexts, 13 - 15 August 1998, Sheffield, Taylor Graham, London, pp. 55-66.

Wilson, T. D. and Streatfield, D. R. (1977), "Information needs in local authority social services departments: an interim report on Project INISS", Journal of Documentation, Vol. 33 No. 4, pp. 277-293.

Wilson, T. D., Streatfield, D. R. and Mullings, C. (1979), "Information needs in local authority social services departments: a second report on Project INISS", Journal of Documentation, Vol. 35 No. 2, pp. 120-136. 
APPENDIX 1: INTERVIEW SCHEDULE FOR ABERDEEN ROADSHOWS

SP/

PARLIAMENTARY INFORMATION INTERNET ROADSHOW

INTERVIEW SCHEDULE

LOCATION:

GROUP:

DATE:

Hello, I'm from the Robert Gordon University in Aberdeen, and I'm doing some research into how information about the Scottish Parliament is presented on the Internet.

I was wondering if you could spare around 15-20 minutes to have a look around the Scottish Parliament website on the Internet, just letting me know what you think of it, and also to answer a few questions about yourself. I'd also like to tape-record part of the interview.

All of your answers will be completely anonymous, and you can refuse to answer any particular question if you want to.

\section{Information about the respondent}

[1] a) Gender.

Male

Female

Could you start by telling me a little bit about yourself.

b) Age group. To which one of the following age groups do you belong?

$\begin{array}{llll}16-19 & \square & 55-64 & \square \\ 20-29 & \square & 65-74 & \square \\ 30-44 & \square & 75 \text { or over } & \square \\ 45-54 & \square & & \end{array}$

c) Ethnic Group. To which one of the following ethnic groups do you belong?

White
Black Caribbean
Black African
Black Other
Indian

d) Status. Are you: In paid employment Self employed Seeking work

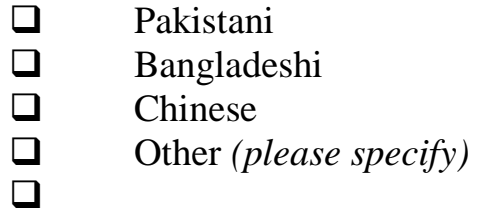

$\begin{array}{ll}\square & \text { Retired } \\ \square & \text { Running a home } \\ \square & \text { Student }\end{array}$

(If in paid employment or self employed) Could you please specify your occupation:- 
e) Educational attainment. What was the highest level of education you completed?

School

Further Education College

University postgraduate

University undergraduate

Doctorate

f) Disability. Would you describe yourself as a disabled person? YES $\square$ NO

g) Place of residence. Do you live locally? YES $\quad \square \quad$ NO

If NO, where do you live?

\section{Past parliamentary information need, levels of participation and experience of ICTs}

[2] Have you ever tried to find information about

the Scottish Parliament

the UK Parliament at Westminster

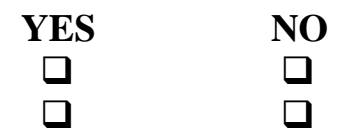

If YES, what kind of information did you try to find?

Where did you go to obtain this information?

[3] Did you vote at the last:

$\begin{array}{lcc} & \text { YES } & \text { NO } \\ \text { Scottish Parliament election } & \square & \square \\ \text { UK General election } & \square & \square \\ \text { European Parliament election } & \square & \square\end{array}$

[4] Apart from voting, would you say that you actively participate in the political process?

YES $\square \quad$ NO

If YES, in what way(s) do you actively participate?

[5] How often do you use a computer?

Regularly $\square \quad$ Occasionally $\square \quad$ Have never used one

(Go straight to period of searching) 
[6] Do you find computers easy to use?

Very easy $\square$ Quite easy $\square$ Quite difficult $\square$ Very difficult $\square \quad$ Not applicable

[7] Have you ever used the Internet?

YES $\square \quad$ NO $\square \quad$ Not applicable

\section{Period of Searching}

I'd now like you to look on the Scottish Parliament website for information on a particular topic. If there's a particular subject you're interested in you could look for information on that. Or I've got a list of topics here that you might want to choose from.

I'm interested in what you think about the website and about the type of information that's actually on it. So I'd like you to try to think aloud as you're looking through the website. What I mean by think aloud, is that I want you to try to tell me everything that you're thinking about as you go along.

It could be what you think about the design of the website: what it looks like and how easy or difficult it is to find your way around it. Or it could be about the information that you actually find: how easy or difficult it is to understand and whether or not it's the sort of information that you think might be useful to you.

So, if you can, just try to act as if you're alone in a room speaking to yourself. And just try to keep talking all the time. If you do stop talking, I'll probably come in with a question for you. And if you could try to speak as loudly and as clearly as possible, because I'll be taperecording you as you go along.

If you've used the Internet before, I should point out that, because we're using a mobile phone to connect to the Internet, we'll only be operating at about half the speed of a normal computer. So, it will be slower than what you're used to.

Do you have any questions about what I'd like you to do?

Time search started:

Time search ended: 


\section{Final questions: evaluative feedback}

[8] Do you think the Scottish Parliament website is a useful way of providing information to the public?

$$
\text { YES } \square \quad \text { NO }
$$

Could you explain why you've responded like this?

[9] How easy to use would you say the Scottish Parliament website is?

Very easy $\square \quad$ Quite easy $\square \quad$ Not easy at all

[10] How interesting did you find the information that you obtained here today?

Very interesting $\square \quad$ Quite interesting $\square \quad$ Not interesting at all

[11] How easy to understand was the information you obtained here today?

Very easy $\square \quad$ Quite easy $\square \quad$ Not easy at all

[12] How relevant do you think this type of information is to your own day-to-day life?

Very relevant $\square \quad$ Quite relevant $\square \quad$ Not relevant at all

[13] If you wanted to find out more about the topic that you were looking at today, how would you go about it? 
[14] Having used the Scottish Parliament website and seen some of the information that's available on it, do you think you might want to use it again in the future?

\section{YES $\square \quad$ NO}

Could you explain why you've responded like this?

That is the end of the interview. If you feel you can spare another few minutes of your time, I'd like you to browse through some of the Scottish Parliament's publications that I've got with me here today, and then answer a few short questions on how you feel they compare with the Scottish Parliament website.

If you feel that you can't spare the time, I'd like to thank you very much for your cooperation and ask you to accept this pen as a small token of my appreciation. 